\title{
Popularity Survey Governor Candidate of Jakarta in 2017 from Social Networks
}

\author{
Muhammad Galih Wonoseto ${ }^{1 *}$, Felix Ngobigha ${ }^{2}$ \\ ${ }^{1}$ Informatic Engineering, UIN Sunan Kalijaga Yogyakarta, Yogyakarta, Indonesia \\ ${ }^{2}$ School of Engineering Arts Science and Technology (EAST), University of Suffolk, Ipswich, England \\ *Corresponding author. Email: muhammad.wonoseto@uin-suka.ac.id
}

\begin{abstract}
This paper proposed a system to survey candidate popularity for governor of Jakarta in 2017 from Twitter, Facebook, Instagram, YouTube, and Google Trends. While traditional surveys take days or weeks to complete, the system demonstrated results instantly and continuously. This paper aims to measure the popularity of gubernatorial candidates through the volume of tweets, number of Facebook posts, number of Instagram hashtags, number of videos on YouTube, and Google Trends. There are four candidates who studied in popularity, Basuki Tjahaya Purnama, Yusril Iza Mahendra, Sandiaga Uno, and Adhyaksa Dault. The most popular is Basuki Tjahaya Purnama, and he entered as a candidate for governor of DKI Jakarta in 2017. It was proved that the popularity survey of gubernatorial candidates using online social networks could be used as an alternative as a substitute for manual/traditional surveys.
\end{abstract}

Keywords: Popularity Survey; Social Networks; Election.

\section{INTRODUCTION}

To win the world political arena, the necessary process of making strategy, execution, and evaluation quickly and accurately. One strategy is to look for famous and acceptable candidates in the community. One way to find out the level of popularity of a candidate is by using a survey method. The results of this survey are essential for any political party, each candidate, the successor team, and competitors to develop a strategy and evaluate its performance over the years. Unfortunately, survey results by survey institutions are often manipulated for the sake of leading opinions. During this time, the survey is still manual. The survey manual method requires much time, a lot of human resources, and cost.

The Ministry of Communications and Information Technology (KEMKOMINFO) expresses that internet users in Indonesia currently reach 63 million people. Of that number, 95 percent use the Internet to access social networking. Some social networks that are widely used are Facebook, Twitter, YouTube, and Instagram. In addition to social networking, search sites are most widely used in Indonesia and worldwide is Google. Google provides service facilities to determine any trends often searched by users of google using google trends. Google also has a video streaming site that Indonesian people frequently use, and the world is YouTube.
For the 2017 governor election of DKI Jakarta, we have developed a tool for real-time analysis of popularity expressed through Twitter, Facebook, Instagram, YouTube, and google trends. With this analysis, we seek to explore whether the Internet provides insights into the unfolding of the campaigns and indications of shifts in public popularity [1].

Social media allows users to post their opinion on their social networks. Social media usage is snowballing. Because social media are accessible, they lend themselves to quick and dynamic expressions of instant reactions to current events. We expect automated realtime popularity analysis of this user-generated data to provide immediate indications of changes in opinion, showing how an audience reacts to a particular candidate's statements during a political debate. The system we present here, along with the dashboards displaying analysis results with drill-down ability, is precisely aimed at generating real-time insight as events unfold. 
Table 1. Advantages

\begin{tabular}{|l|l|}
\hline \multicolumn{1}{|c|}{ Current System } & Proposed System \\
\hline Expensive & Cheap \\
\hline Took a long time & Real-time \\
\hline $\begin{array}{l}\text { Requires a lot of human } \\
\text { resources }\end{array}$ & $\begin{array}{l}\text { Requires little human } \\
\text { resources }\end{array}$ \\
\hline
\end{tabular}

Table 2. Disadvantages

\begin{tabular}{|l|l|}
\hline Current System & Proposed System \\
\hline $\begin{array}{l}\text { More represent all } \\
\text { emements of society }\end{array}$ & $\begin{array}{l}\text { It cannot represent all } \\
\text { elements of society }\end{array}$ \\
\hline
\end{tabular}

\section{RELATED WORK}

In the last decade, interest in mining sentiment and opinions in the text has overgrown due to the significant increase in the availability of documents and messages expressing personal opinions (Pang \& Lee, 2008) [2]. In particular, sentiment in Twitter data has been used for predictor or measurement in a variety of domains, such as stock market, politics, and social movements (Bollen et al., 2011; Choy et al., 2011; Tumasjan et al., 2010; Zeitzoff, 2011) [3] [4] [5] [6]. For example, Tumasjan (2010) found tweet volume about the political parties to be a good predictor for the outcome of the 2009 German election, while Choy et al. (2011) failed to predict with Twitter sentiment the ranking of the four candidates in Singapore's 2011 president election.

In November 2012, at the presidential election, United States, Hao Wang, Dogan Can, Kazemzadeh, Francois and Shrikanth, built a system for real-time Twitter sentiment analysis of the 2012 U.S. presidential election cycle. They analyzed nine candidates who will oppose Barack Obama as the incumbent president.

Four candidates are more popular than the other; Gingrich, Romney, Ron Paul, dan Santorum. The result is that Romney is the most popular and most talked by the citizen, but negatively. The most positive opinion, obtained by Santorum. Moreover, the most more minor negative opinion is obtained by Gingrich.

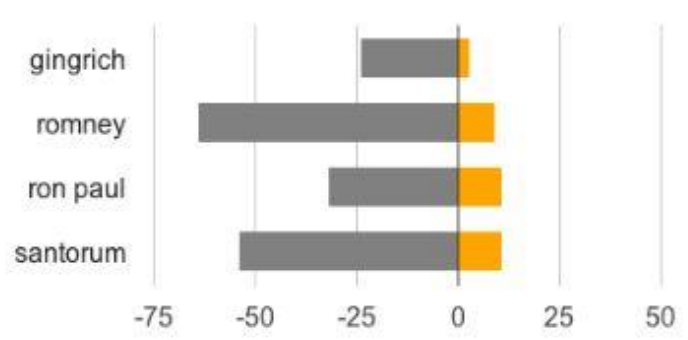

Figure 1 Sentiment analysis result of 2012 U.S. presidential election cycle [1]

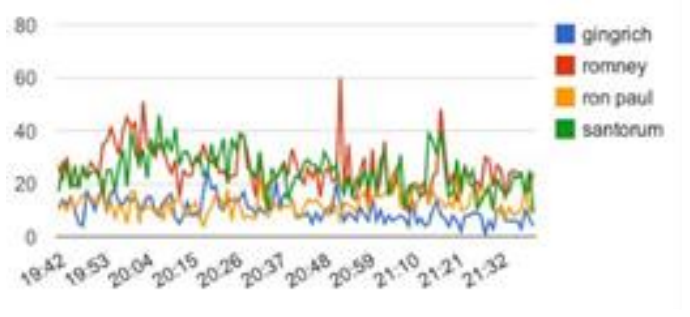

Figure 2 Tweets volume of 2012 U.S. presidential election cycle [1]

Romney had been the most potent rival Obama, not Santorum among the four candidates. It is indicated that the correct method to calculate the candidate's popularity is to count the number of tweets for the candidate without analyzing whether it is positive or negative.

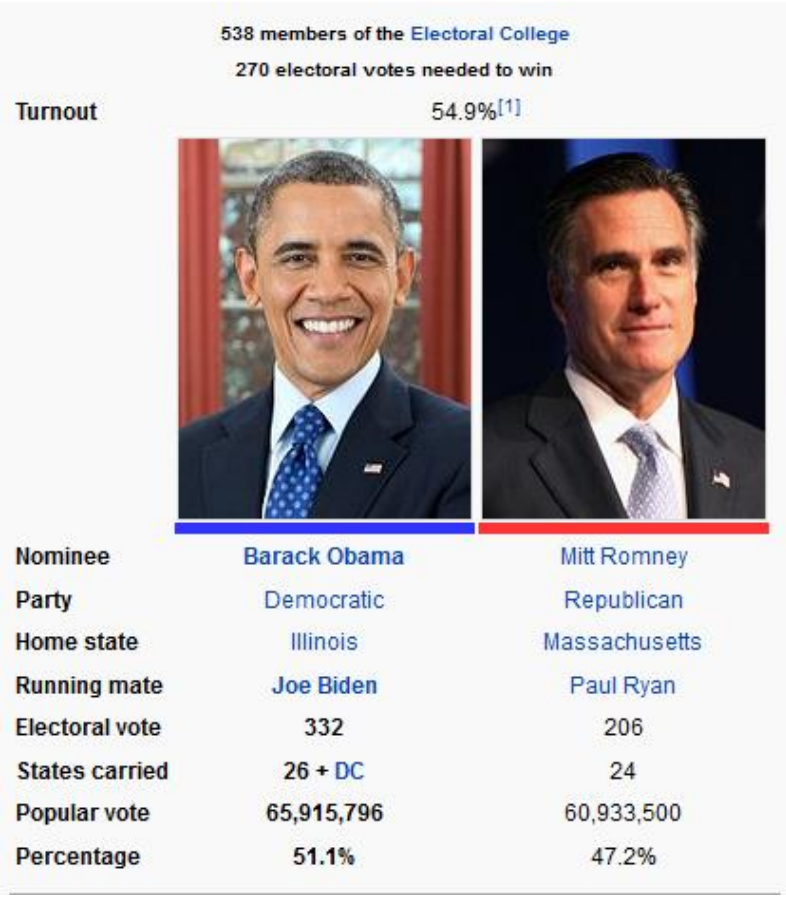

Figure 3 Result of 2012 U.S. President Election

\section{THE SYSTEM}

\subsection{Overview System}

The primary purpose of this system is to enable users to determine the level of popularity of the candidates for governor of Jakarta in 2017. Information about the popularity of the candidates for governor of Jakarta in 2017 is required by candidates, political parties, and the campaign team. 


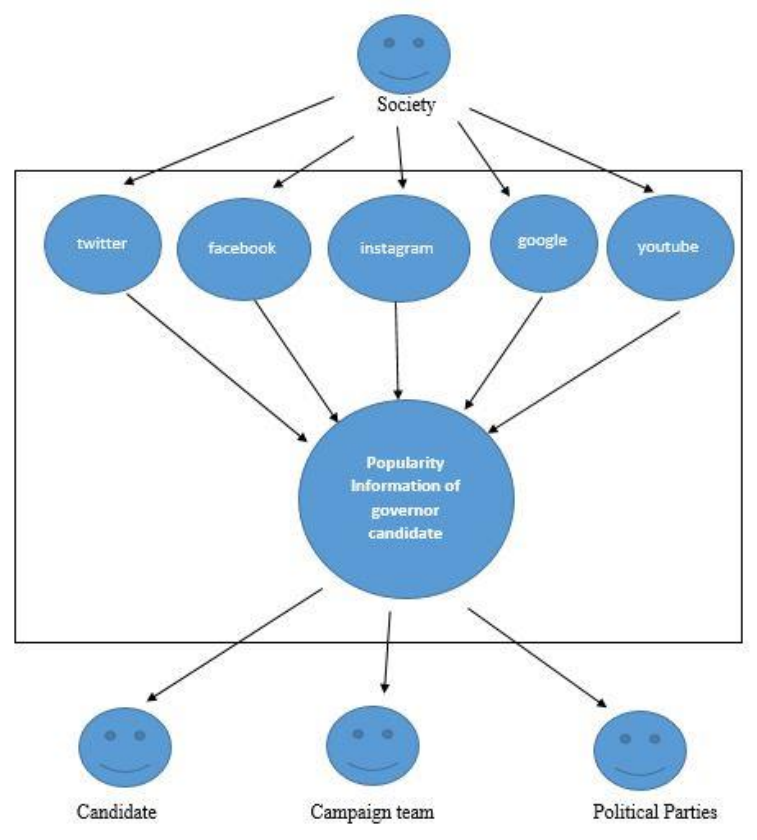

Figure 4 System Overview

Data processing starts streaming the data with the API of Twitter and using the manual method for other social networks, classified based on the candidate, do the calculation, and the last is visualized with graphics on the system are made.

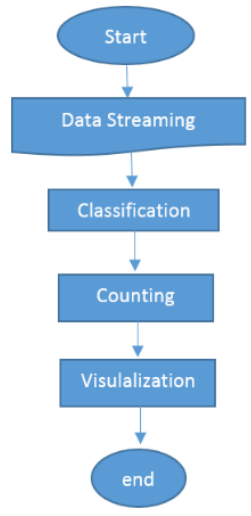

Figure 5 Flowchart Data Process

\subsection{Input/ Data Sources}

Data Sources from the system that was built in obtaining information extraction popularity Jakarta governor candidate in 2017 consists of:
1. Twitter
2. Facebook
3. Instagram
4. Google trends
5. YouTube

\subsection{Classification}

The data from social media and web 2.0 tools then classified based on each candidate. There are Basuki Tjahja Purnama (Ahok), Adhyaksa Dault, Yusril Izha Mahendra, and Sandiaga Salahudin Uno.

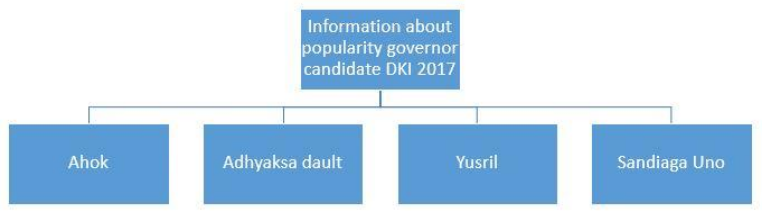

Figure 6 Classification

\subsection{Display and Visualization}

The system displayed 5 data visualization for each social network and web 2.0 tool. Data visualization Twitter displays the tweet volume and the number of user id given tweets. The visualization update data every 5 seconds. We chose to display the volume of tweets and the number of user id given tweets as information popularity of each candidate. Data visualization Facebook displays the number of people talking about the candidate. Data visualization Instagram displays the number of total hashtags about the candidate. Data visualization YouTube displays the number of total videos about the candidate. Data visualization google trends display the number of total searches about the candidate in google.

\section{IMPLEMENTATION}

\subsection{Technological Implementation}

\subsubsection{Node JS}

This system uses Node.js for the implementation. Node.js is a server-side JavaScript environment. Node.js based on Google's runtime implementation - the aptly named "V8" engine [7]. For the implementation, we use node JavaScript to get data from Twitter by API.

\subsection{2. $M y S Q L$}

MySQL is available for many different operating systems on a variety of computer architectures. The availability of cross-platform versions has enhanced the popularity of MySQL [8]. We use MySQL at XAMPP as the database

\subsection{3. $P H P$}

PHP is a server scripting language and a powerful tool for making dynamic and interactive Web pages. PHP is a widely-used, accessible, and efficient alternative to competitors such as Microsoft's ASP. We use PHP to 
build our website because it makes our website more dynamic and interactive.

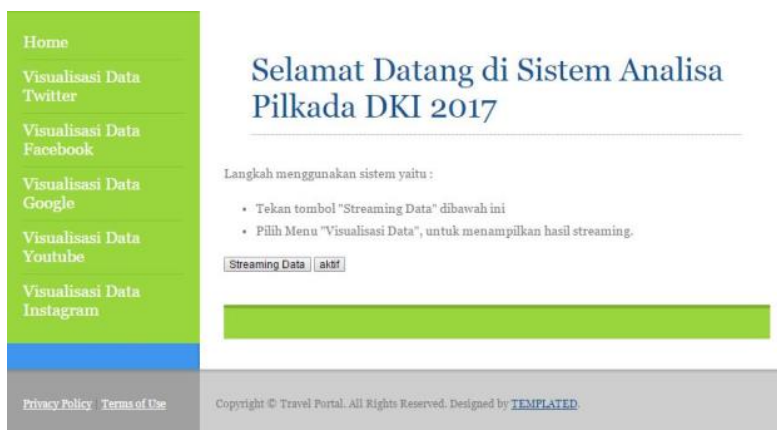

Figure 7 Graphic User Interface

\section{RESULT}

\subsection{Twitter}

Table 3 shows the result of the stream as much as three times on three different days.

Table 3. Streaming Result

\begin{tabular}{|l|l|l|l|}
\hline \multicolumn{1}{|c|}{ Name } & \multicolumn{3}{c|}{ Date } \\
\hline & $\mathbf{0 5 / 0 5 / 2 0 1 6}$ & $\mathbf{0 6 / 0 5 / 2 0 1 6}$ & $\mathbf{0 7 / 0 5 / 2 0 1 6}$ \\
\hline Ahok & 24 & 1625 & 2 \\
\hline Yusril & 0 & 445 & 407 \\
\hline Sandiaga & 0 & 0 & 0 \\
\hline Adhyaksa & 0 & 55 & 0 \\
\hline
\end{tabular}

From the graph above, it can be seen that the most popular candidate is Basuku Tjahaya Purnama (Ahok). Furthermore, the second is Yusril, number three is Adhyaksa, and number four is Sandiaga Uno. It was based on the number of tweets. However, it could be an account to tweet many times when it only represents one person's opinion.

Then, we need to look at the number of users in the text. It is shown in Table 4.

Table 4. Total Tweet Volume and User-id

\begin{tabular}{|l|l|l|l|}
\hline \multicolumn{1}{|c|}{ Name } & \multicolumn{3}{c|}{ Date } \\
\hline & $\mathbf{0 5 / 0 5 / 2 0 1 6}$ & $\mathbf{0 6 / 0 5 / 2 0 1 6}$ & $\mathbf{0 7 / 0 5 / 2 0 1 6}$ \\
\hline Ahok & 24 & 1625 & 2 \\
\hline Yusril & 0 & 445 & 407 \\
\hline Sandiaga & 0 & 0 & 0 \\
\hline Adhyaksa & 0 & 55 & 0 \\
\hline
\end{tabular}

Basuki Tjahaya Purnama is still the most popular based on user-id. The second is Yusril, number three is Adhyaksa, and number four is Sandiaga Uno.

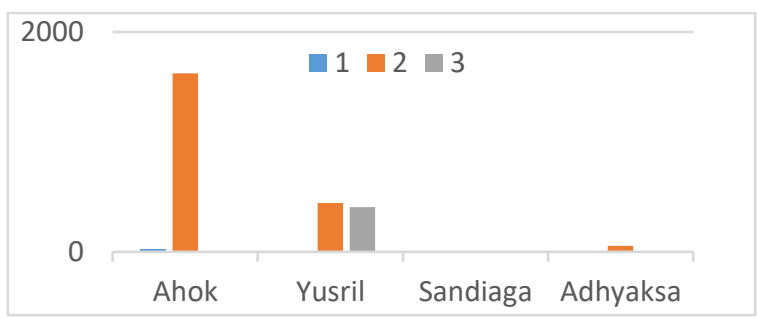

Figure 8 Tweet Volume at Three Days

On the third day, the number of tweets Yusril was more than Ahok. It was indicated that an increase in the popularity of Yusril. It can be concluded that the most popular candidate is Ahok, and the most likely candidate is increasing in popularity is Yusril.

\subsection{Facebook}

This data was collected manually on 24 May 2016. Facebook provides data on the number of talks about each candidate.

Table 5. Total Post in Facebook

\begin{tabular}{l|l|l|c}
\hline \multicolumn{4}{c}{ People Talking About The Candidates } \\
\begin{tabular}{|c|c|c|} 
Basuku Tjahaja \\
Purnama
\end{tabular} & $\begin{array}{l}\text { Adhyaksa } \\
\text { Dault }\end{array}$ & $\begin{array}{l}\text { Yusril Ihza } \\
\text { Mahendra }\end{array}$ & $\begin{array}{l}\text { Sandiaga } \\
\text { Salahuddin Uno }\end{array}$ \\
\hline 98895 & 36381 & 91899 & 90334 \\
\hline
\end{tabular}

\subsection{Google Trends}

This is a data visualization of google trends from 24 April 2016 to 24 May 2016

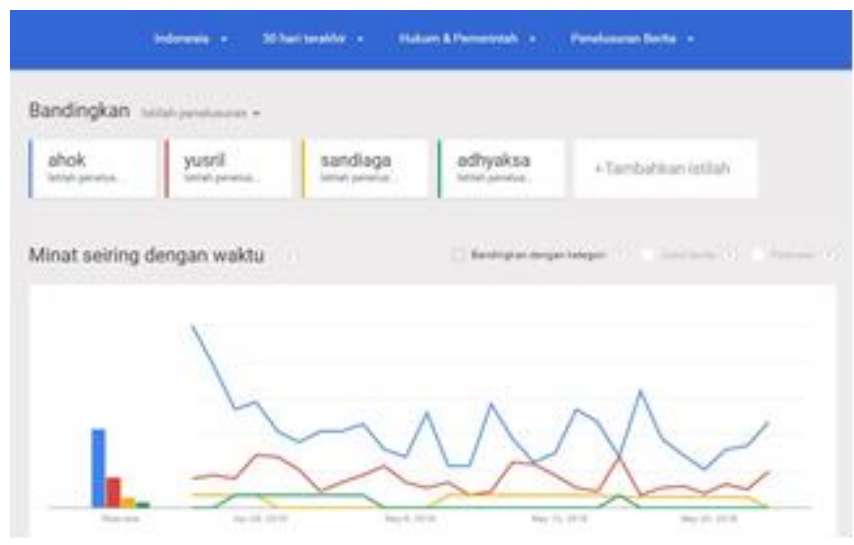

Figure 9 Google Trends Data 


\subsection{Instagram}

This data was collected manually on 24 May 2016. Instagram provides data on the number of hashtags about each candidate

Table 6. Number of Instagram Hastags

\begin{tabular}{|l|c|c|c|}
\hline \#ahok & \#adhyaksa & \#yusril & \#sandiagauno \\
\hline 69.224 & 213 & 1.115 & 1.109 \\
\hline
\end{tabular}

\subsection{YouTube}

This data was collected manually on 24 May 2016. YouTube provides data on the total number of videos about each candidate.

Table 7. Number of Videos in YouTube

\begin{tabular}{|l|l|l|l|}
\hline \#ahok & \#adhyaksa & \#yusril & \#sandiagauno \\
\hline 821.000 & 18.800 & 80.500 & 23.800 \\
\hline
\end{tabular}

\section{ANALISYS}

This chapter will compare the results of the 2017 Jakarta gubernatorial candidate popularity survey on various social networks. In addition, we will also compare it with the reality of the results of the 2017 DKI Jakarta Pilkada in the first round. Table 8 is a comparison table of popularity rankings between candidates on various social networks.

Table 8. Comparison of Popularity Rankings Among Candidates on Various Social Networks

\begin{tabular}{|l|l|l|l|l|l|}
\hline Rank & Twitter & Facebook & $\begin{array}{l}\text { Google } \\
\text { Trend }\end{array}$ & Instagram & Youtube \\
\hline 1 & Ahok & Ahok & Ahok & Ahok & Ahok \\
\hline 2 & Yusril & Yusril & Yusril & Yusril & Yusril \\
\hline 3 & Adhyaksa & Sandi & Sandi & Sandi & Sandi \\
\hline 4 & Sandi & Adhyaksa & Adhyaksa & Adhyaksa & Adhyaksa \\
\hline
\end{tabular}

Based on the results of the political dynamics at that time, several pairs of candidates for the 2017 DKI Jakarta governorship emerged:

- AHY- Sylviana Murni

- $\quad$ Ahok-Djarot

- $\quad$ Anies-Sandi
Ahok's success in becoming the strongest candidate for the 2017 DKI Jakarta gubernatorial candidate and obtaining the most votes in the first round of the 2017 DKI Jakarta election proves that popularity surveys using Twitter can be used as an alternative to using manual surveys.

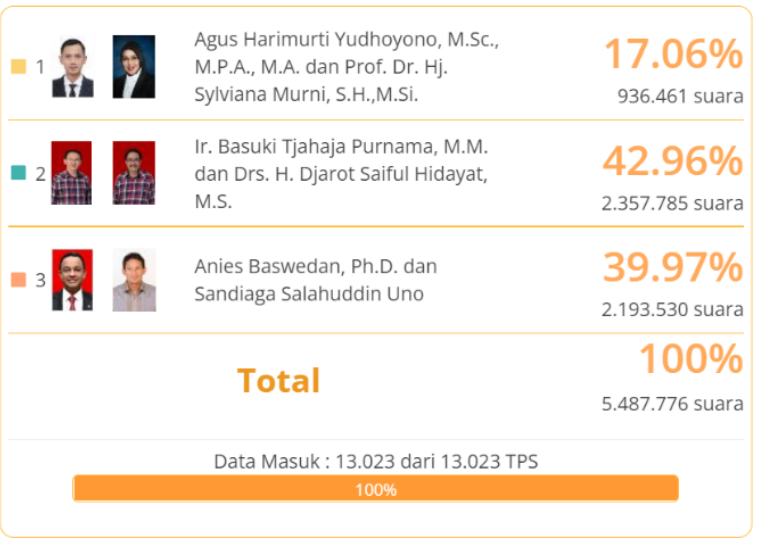

Figure 10 TPS Count Results (Form C1) DKI Jakarta Province [9]

\section{CONCLUSION AND RECOMMENDATION}

Based on the data and facts found during the study, it can be concluded several things including:

- Both using tweet volume and user id, the results of candidate popularity ranking remain the same.

- The most popular candidate in all social networks is Ahok.

- This is the same with the reality that Ahok is the winner in the first election.

The ranking order is the same in all social networks except twitter.

Based on the research analysis above, it can be concluded that measuring the popularity of governor candidates through social networks can be used as an alternative to manual/traditional surveys that take a lot of time and money.

\section{REFERENCES}

[1] Wang, Hao, et al, "A System for Real-time Twitter Sentiment Analysis of 2012 U.S. Presidental Election Cycle", Proceeding of the 50th Annual of the Association for Computational Linguistics, 2012, pp 115-120.

[2] Pang, B., \& Lee, L, “Opinion Mining and Sentiment Analysis", Foundations and Trends in Information Retrieval, 2 (1-2), 2008, pp 1-135, doi: $10.1561 / 1500000011$ 
[3] Bollen, J., Mao, H., \& Zeng, X, "Twitter mood predicts the stock market", Journal of Computational Science, 2(1), 2011, pp 1-8, doi: 10.1016/j.jocs.2010.12.007.

[4] Choy, M. et al, "A sentiment analysis of Singapore Presidential Election 2011 using Twitter data with census correction", Research Collection School of Information Systems, 2012.

[5] Tumasjan, A., Sprenger, T. O., Sandner, P. G., \& Welpe, I. M, "Predicting Elections with Twitter: What 140 Characters Reveal about Political Sentiment", Proceedings of the International AAAI Conference on Web and Social Media, Vol. 4, No. $1,2010$.
[6] Zeitzoff, T., "Using Social Media to Measure Conflict Dynamics: An application to the 20082009 Gaza conflict.", Journal of Conflict Resolution, 55 (6), 2011, pp 938-969, doi: $10.1177 / 0022002711408014$.

[7] Tilkov S., Vinoski S., "Node.js: Using JavaScript to building High Performance network Programs", IEEE Internet Computing 14.6, Nov 2010, pp. 8083.

[8] Suehring S., "Mysql Bible", Wiley Publishing, Inc., New York, 2002.

[9] KPU at https://pilkada2017.kpu.go.id 